\title{
Karyotypes and Repetitive DNA Evolution in Six Species of the Genus Mahanarva (Auchenorrhyncha: Cercopidae)
}

\author{
Allison Anjos ${ }^{a}$ Gabriela C. Rocha ${ }^{a}$ Andressa Paladini ${ }^{c}$ Tatiane C. Mariguelab \\ Diogo C. Cabral-de-Mello ${ }^{a}$ \\ a Departamento de Biologia, and ${ }^{\mathrm{b}}$ Departamento de Zoologia, Instituto de Biociências, UNESP, Rio Claro, and \\ 'Faculdade de Biociências, Pontifícia Universidade Católica do Rio Grande do Sul, Porto Alegre, Brazil
}

\section{Key Words}

Agricultural pests · Heterochromatin · Holocentric

chromosomes $\cdot$ Repetitive DNAs · Telomeres

\begin{abstract}
Insects of the Cercopidae family are widely distributed and comprise 59 genera and 431 species in the New World. They are xylemophagous, causing losses in agricultural and pasture grasses, and are considered as emerging pests. Chromosomally, these insects have been studied by standard techniques, revealing variable diploid numbers and primarily $X_{0}$ sex chromosome systems (males). We performed chromosome studies in 6 Mahanarva (Cercopidae) species using standard and differential chromosome staining as well as mapping of repetitive DNAs. Moreover, the relationship between the repetitive DNAs was analyzed at the interspecific level. A diploid chromosome number of $2 n=19$, X0 was documented, with chromosomes gradually decreasing in size. Neutral or GC-rich regions were detected which varied depending on the species. Fluorescence in situ hybridization with a (TTAGG) ${ }_{n}$ telomeric motif probe revealed terminal signals, matching those of the Cot DNAs obtained from each species, that were also restricted to the terminal regions of all chromosomes. Dot blot analysis with the Cot fraction
\end{abstract}

\section{KARGER}

(c) 2016 S. Karger AG, Basel

E-Mail karger@karger.com

www.karger.com/cgr from M. quadripunctata showed that at least part of the repetitive genome is shared among the 6 species. Our data highlight the conservation of chromosomal features and organization of repetitive DNAs in the genus Mahanarva, suggesting a low differentiation for chromosomes and repetitive DNAs in most of the 6 species studied.

(c) 2016 S. Karger AG, Basel

Cercopidae belong to the hemipteran infraorder $\mathrm{Ci}$ cadomorpha, suborder Auchenorrhyncha. These insects are distributed worldwide and represent the largest cercopoid family, with 431 species grouped in 59 genera in the New World [Carvalho and Webb, 2005; Cryan and Urban, 2012; Paladini and Cryan, 2012]. They are xylemophagous insects, and due to this habit, they cause losses in agricultural and pasture grasses, as pests of forage grasses, sugarcane, and occasionally other cultivated grass, such as rice [Bernardo et al., 2003; Peck and Thompson, 2008]. At least 11 genera of Cercopidae are considered emerging pests, including Mahanarva, with 39 species widely distributed in South and Central America [Paladini and Carvalho, 2007].

Chromosomal studies in Auchenorrhyncha have been performed in $\sim 820$ species, mostly using standard chro- 
mosome staining with description of diploid numbers, that range from $2 n=8$ to $2 n=38$ in females, and sex chromosomes, revealing predominance of XX이 $0 \sigma^{\top}$ [Boring, 1913; Halkka, 1964; Dey, 1991; Kuznetsova and AguinPombo, 2015]. For Cercopidae, 31 species were karyotyped showing variability for diploid number and sex chromosomes, e.g., $2 \mathrm{n}=28$, XYo" in Cosmoscarta species (C. dimidiata, C. septempunctata, C. decisa, C. egens, and C. fulviceps); $2 \mathrm{n}=19, \mathrm{X} 0 \mathrm{o}^{\mathrm{T}}$ in Mahanarva fimbriolata, M. posticata, and Deois flavopicta; and $2 \mathrm{n}=15, \mathrm{X} 0 \mathrm{o}^{\mathrm{T}}$ in Notozulia entreriana [Dey, 1991; Marin-Morales et al., 2002; Castanhole et al., 2010].

Repetitive DNAs are abundant in eukaryotic genomes, including in-tandem and dispersed elements, and could play an important role in genome and chromosome diversification [Cavalier-Smith, 1982; Charlesworth et al., 1994; Elder and Turner, 1995; Kidwell, 2002; Feschotte and Pritham, 2007]. These repetitive sequences represent excellent chromosomal markers and have been successfully used for the understanding of chromosomal evolution in distinct insect orders [e.g., Palomeque and Lorite, 2008; Nguyen et al., 2010; Anjos et al., 2015]. In species with holocentric chromosomes, repetitive DNA markers are even more important to understand evolution, due to the lack of other chromosomal features, such as the primary constriction, allowing the identification of specific chromosomes or chromosomal regions [Pita et al., 2014; Kuznetsova and Aguin-Pombo, 2015].

Among insects with holocentric chromosomes, the organization of heterochromatin has mostly been studied by conventional techniques, and studies using isolated repetitive fractions or specific repetitive DNAs have been undertaken in a few species [Kuznetsova et al., 2009; Bardella et al., 2014; Pita et al., 2014; Kuznetsova and Aguin-Pombo, 2015]. The telomeric repeat (TTAGG) $)_{n}$ is considered ancestral for arthropods [Vítková et al., 2005], although in insects this motif was repeatedly lost [Frydrychová et al., 2004], including representatives of distinct orders, like Coleoptera, Hemiptera, Diptera [Frydrychová et al., 2004], and Hymenoptera [Gokhman et al., 2014].

Here, we performed chromosome studies in 6 species of Mahanarva applying standard staining and banding techniques, and FISH with the ancestral arthropod telomeric motif (TTAGG) $)_{n}$. In addition, a repetitive DNAenriched fraction (Cot-DNA) was obtained for each species, and the location of the pool of repetitive DNAs was established by FISH to the species of origin. The conservation of the repetitive DNA pools between the 6 species was tested by cross-hybridization using dot blot assays. The similarities and differences in the chromosomal

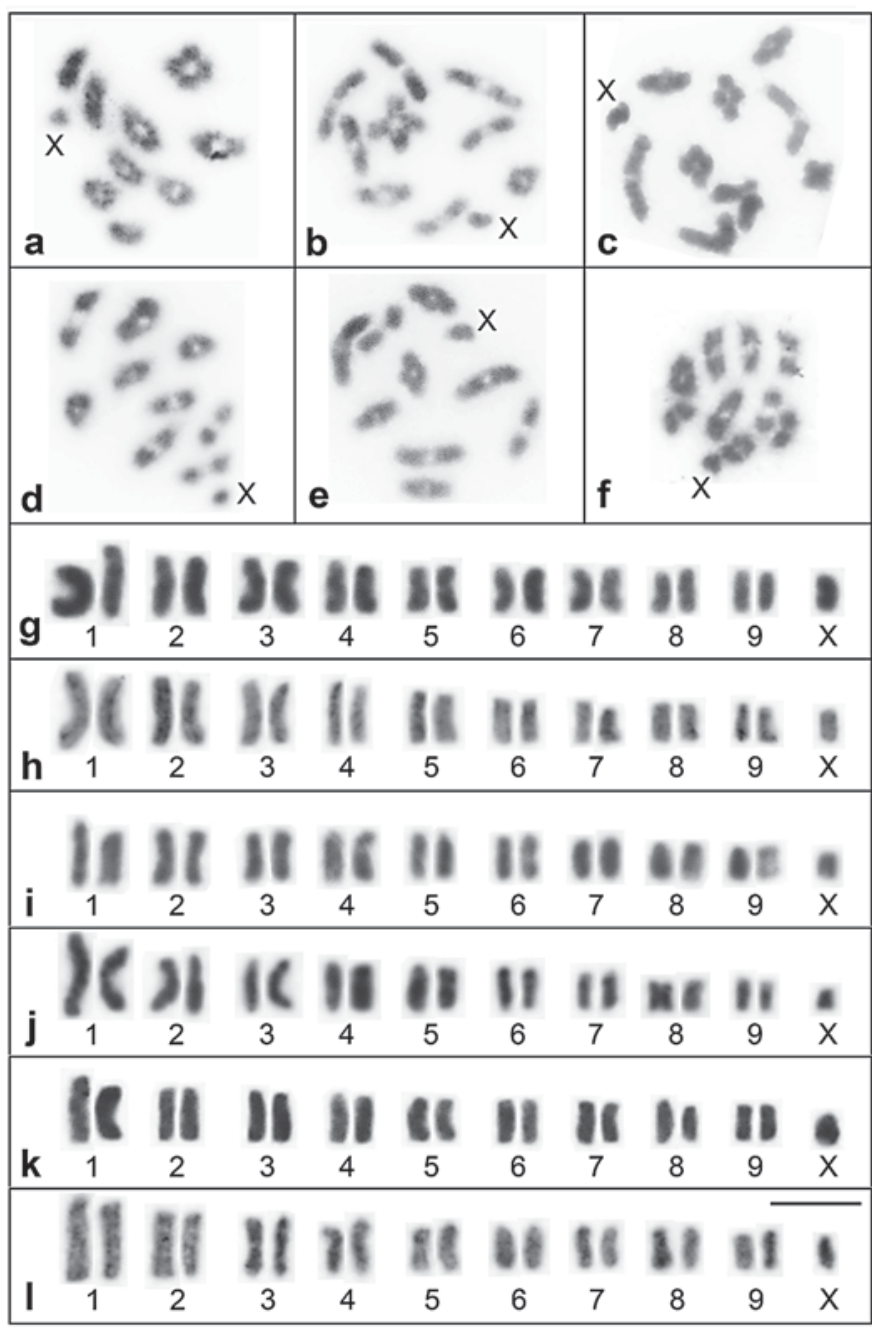

Fig. 1. Meiotic (a-f) and mitotic (g-l) chromosomes of 6 Mahanarva species stained with $5 \%$ Giemsa. a, $\mathbf{g}$ M. fimbriolata; $\mathbf{b}, \mathbf{h} M$. liturata; c, i M. quadripunctata; d, j M. spectabilis; e, k M. tristis; f, I M. vittata. a-c, e Diakinesis; d, f metaphase I; $\mathbf{g}-\mathbf{I}$ arranged karyotypes. In a-f, the X chromosome is indicated. Bar $=5 \mu \mathrm{m}$.

markers were used to infer the evolutionary processes that led to chromosomal and repetitive DNA diversification in the species studied.

\section{Materials and Methods}

Adult males of 6 Mahanarva species (M. fimbriolata, M. liturata, $M$. quadripunctata, $M$. spectabilis, $M$. tristis, and $M$. vittata) were sampled in natural areas of Rio Claro, São Paulo State, Brazil. Animals were anesthetized, the testes were dissected, left in distilled water for $5 \mathrm{~min}$, and then fixed in modified Carnoy's solution (absolute ethanol:acetic acid, 3:1). Whole animals were stored in 

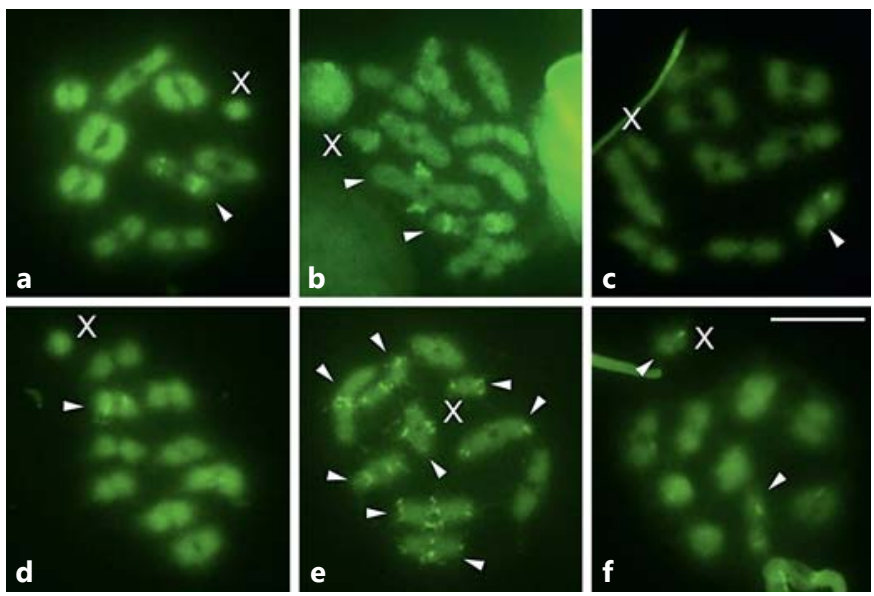

Fig. 2. Fluorochrome staining with $\mathrm{CMA}_{3}$ in meiotic cells of $6 \mathrm{Ma}$ hanarva species. a $M$. fimbriolata; b $M$. liturata; c $M$. quadripunctata; d M. spectabilis; e M. tristis; $\mathbf{f}$ M. vittata. b, e Diakinesis; a, c, d, $\mathbf{f}$ metaphase I. The X chromosome is indicated, and chromosomes bearing positive signals are shown with arrowheads. Bar = $5 \mu \mathrm{m}$.

$100 \%$ ethanol for DNA extraction, following the protocol of Sambrook and Russell [2001], and for species identification. The testis follicles were macerated in a drop of $50 \%$ acetic acid, and the slides were dried using a hot plate at $40-45^{\circ} \mathrm{C}$ for chromosome preparation. The chromosomes were stained with $5 \%$ Giemsa, and fluorochrome staining with chromomycin $\mathrm{A}_{3}$ /distamycin A/DAPI $\left(\mathrm{CMA}_{3} / \mathrm{DA} / \mathrm{DAPI}\right)$ was performed as proposed by Schweizer et al. [1983].

The telomeric probe was obtained through PCR using the complementary primers (TTAGG) ${ }_{5}$ and (CCTAA) ${ }_{5}$ following the protocol of Ijdo et al. [1991]. Cot-DNA samples (DNA enriched for highly and moderately repetitive DNA sequences) were obtained according to the protocol described by Zwick et al. [1997] using the reannealing time of $25 \mathrm{~min}$.

FISH was performed according to the protocol of Pinkel et al. [1986], with modifications described by Cabral-de-Mello et al. [2010]. The telomeric probe was labeled with digoxigenin-11dUTP (Roche, Mannheim, Germany) through PCR, and Cot-DNA fractions were labeled with biotin-14-dATP through nick translation (Invitrogen, San Diego, Calif., USA). Probes labeled with digoxigenin-11-dUTP were detected using anti-digoxigenin rhodamine (Roche), and probes labeled with biotin-14-dATP were detected using Streptavidin Alexa Fluor 488 (Invitrogen). All preparations were counterstained with DAPI and mounted in Vectashield (Vector, Burlingame, Calif., USA). Chromosomes and signals were observed using an Olympus microscope BX61 equipped with a fluorescence lamp and appropriate filters. Photographs were recorded with a DP70 cooled digital camera. The images were merged and optimized for brightness and contrast with Adobe Photoshop CS2.

For dot blot analysis, the biotin-14-dATP-labeled Cot-DNA fraction of $M$. quadripunctata was used as probe. Approximately $100 \mathrm{ng}$ of genomic DNA from each of the 6 Mahanarva species was applied to a Hybond $\mathrm{N}+$ nylon membrane (GE Healthcare) and

Karyotypes and Repetitive DNA

Evolution in the Genus Mahanarva
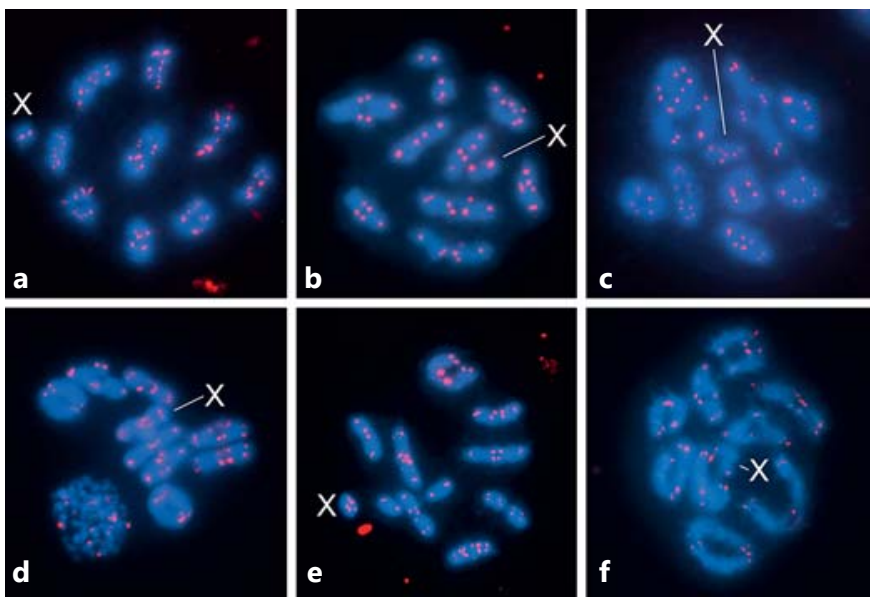

Fig. 3. FISH using the telomeric motif (TTAGG) ${ }_{\mathrm{n}}$ in meiotic chromosomes of 6 Mahanarva species. a M. fimbriolata; $\mathbf{b}$ M. liturata; c $M$. quadripunctata; d M. spectabilis; e M. tristis; $\mathbf{f}$ M. vittata. a, b, d, e Metaphase I; c diakinesis; $\mathbf{f}$ diplotene. The X chromosome is indicated in each cell. Bar $=5 \mu \mathrm{m}$.

denatured with $0.5 \mathrm{M} \mathrm{NaOH}$ for $2 \mathrm{~min}$. The membranes were then washed in $5 \times$ SSC for $1 \mathrm{~min}$. Next, the membrane was dried for 90 $\min$ at $80^{\circ} \mathrm{C}$. The hybridization was carried out overnight $(16 \mathrm{~h})$ at $37^{\circ} \mathrm{C}$ using $200 \mathrm{ng}$ of denatured labeled probe diluted in ECL gold hybridization buffer hybridization solution (GE Healthcare), with the addition of bovine serum albumin $(0.05 \% \mathrm{w} / \mathrm{v})$ and $\mathrm{NaCl}$ $(2.5 \mathrm{M})$. After hybridization, the membrane washes were performed as follows: $5 \times \mathrm{SSC}$ for $5 \mathrm{~min}$ at $42^{\circ} \mathrm{C}$; 3 times in primary buffer containing $6 \mathrm{M}$ urea, $0.4 \%$ SDS (w/v), and $0.1 \times$ SSC for 10 $\min$ at $42^{\circ} \mathrm{C}$ each; and $20 \times \mathrm{SSC}$ for $5 \mathrm{~min}$ at room temperature. Finally, the biotin chromogenic detection kit (K0661, Thermo Scientific) was used, following the manufacturer's recommendations for detection.

\section{Results}

All 6 Mahanarva species showed $2 \mathrm{n}=19, \mathrm{X} 0 \sigma^{7}$ (fig. 1), with holocentric chromosomes decreasing gradually in size (fig. 1g-1). This pattern made the accurate identification of each pair difficult for meiotic cells, except for the $\mathrm{X}$ chromosome, which can be observed as a univalent during meiosis (fig. 1a-f). Fluorochrome staining was homogeneous for DAPI in all species (results not shown), but distinct patterns were detected for $\mathrm{CMA}_{3}$ (fig. 2): interstitial blocks in 1 autosomal bivalent of $M$. fimbriolata, M. quadripunctata, and M. spectabilis (fig. 2a, c, d); 2 bivalents with GC-rich blocks, 1 located interstitially and the other terminally, in M. liturata (fig. 2b); an interstitial block in 1 autosomal bivalent and in 1 terminus of the $\mathrm{X}$ 

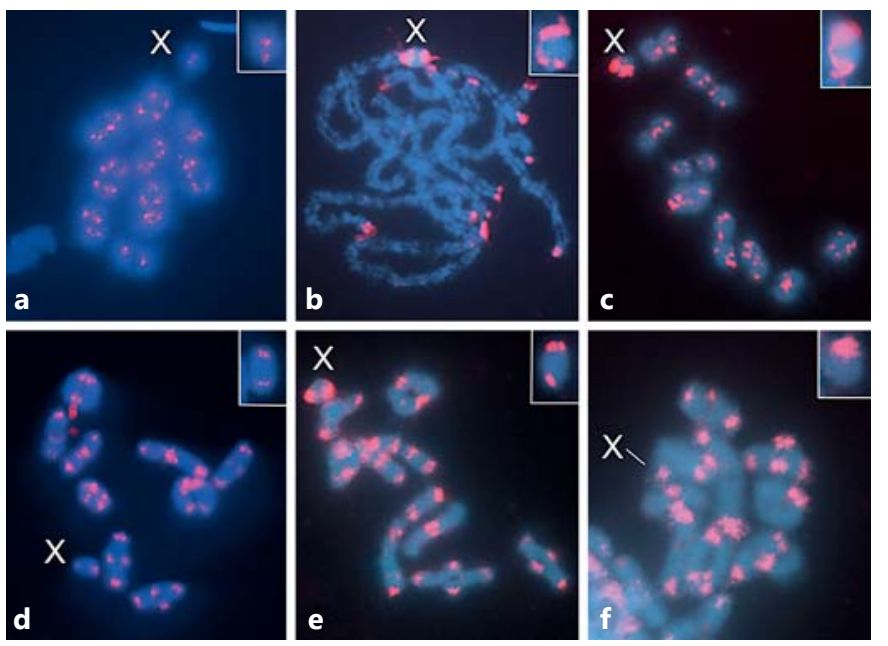

Fig. 4. FISH mapping of the Cot-DNA fraction obtained from each species (self-FISH) in meiotic cells. a $M$. fimbriolata; b $M$. liturata; c M. quadripunctata; d M. spectabilis; e M. tristis; $\mathbf{f}$ M. vittata. a, c-f Metaphase I; $\mathbf{b}$ pachytene. The X chromosome is indicated in each cell and is highlighted in the insets. Bar $=5 \mu \mathrm{m}$.

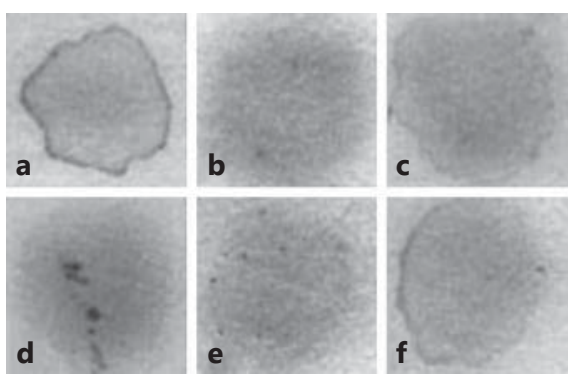

Fig. 5. Labeled Cot-DNA obtained from M. quadripunctata hybridized on a membrane with Mahanarva species unlabeled genomic DNAs. a M. quadripunctata; b M. liturata; c M. spectabilis; d $M$. vittata; e $M$. tristis; $\mathbf{f} M$. fimbriolata.

chromosome in M. vittata (fig. 2f); and multiple sites, including 7 autosomal pairs and the $\mathrm{X}$ chromosome in $M$. tristis. For $M$. tristis, 2 autosomes presented signals in 1 terminus, 4 showed signals in both termini, 1 showed an interstitial signal, and the $\mathrm{X}$ harbored signals in both termini (fig. 2e).

The telomeric motif was restricted to the terminal regions of all chromosomes (fig. 3). These terminal regions were also strongly labeled with the Cot-DNA fraction obtained from each species, revealing stronger signals than those of the telomeric probes (fig. 4). A remarkable difference between the species for the location of Cot-DNA was the presence of only 1 terminal block in the X chro- mosome of $M$. vittata (fig. 4f), while the other species exhibited blocks in both X chromosome termini (fig. 4a-e). Finally, the dot blot using the Cot-DNA fraction obtained from M. quadripunctata as a probe revealed positive hybridization against the genomic DNA of the other Mahanarva species (fig. 5).

\section{Discussion}

Chromosomal studies in Cercopidae are scarce, and for Mahanarva, the karyotypes of $M$. fimbriolata and $M$. posticata were previously described [Marin-Morales et al., 2002]. Invariably, the 7 Mahanarva species studied until now share $2 \mathrm{n}=19, \mathrm{X} 00^{\circ}$, and this could represent the plesiomorphic character for the genus, which is also observed in other Cercopidae species, such as D. flavopicta [Castanhole et al., 2010], although other additional species should be karyotyped. Considering the ancestral diploid number for Cercopoidea, i.e., $2 \mathrm{n}=26-28$ [Kuznetsova and Aguin-Pombo, 2015], Mahanarva has a derived constitution that originated most parsimoniously through chromosomal fusions, leading to a reduction in 2 n. Although extensive variability in diploid numbers has been reported in Auchenorrhyncha in high rank taxa such as tribes, families, and subfamilies [Kuznetsova and Aguin-Pombo, 2015], species within the same genus could present more stable karyotypes as noticed here for Mahanarva, and in Cosmoscarta [Dey, 1991] and Alebra [Kuznetsova et al., 2013].

The telomeric probe (TTAGG) $)_{n}$ did not identify internal telomeric repeats that could be the result of chromosomal fusion suggested here for Mahanarva. The (TTAGG) $)_{\mathrm{n}}$ internal sequences could have been lost during chromosomal evolution, or may not have been identified due to low repeat numbers and classical FISH technique resolution limitations. The (TTAGG) $)_{\mathrm{n}}$ motif is canonical and considered ancestral for insects and arthropods as a whole [Sahara et al., 1999; Frydrychová et al., 2004], although it has been variably lost during the evolution of some orders, such as Diptera, Coleoptera, Hymenoptera, and Hemiptera [Sahara et al., 1999; Frydrychová et al., 2004; Gokhman et al., 2014]. Among hemipterans, the apomorphic heteropterans Cimicomorpha (families Miridae, Cimicidae, and Tingidae) and Pentatomomorpha (families Pyrrhocoridae and Pentatomidae) lost the (TTAGG) $)_{\mathrm{n}}$ ancestral motif [Frydrychová et al., 2004; Grozeva et al., 2011; Golub et al., 2015]. However, (TTAGG) ${ }_{\mathrm{n}}$ was not lost in other groups, including 4 aphid species [Monti et al., 2011], in the coccid Planococcus li- 
lacinus [Mohan et al., 2011], in the suborder Coleorrhyncha [Kuznetsova et al., 2015], in the heteropteran infraorder Nepomorpha [Kuznetsova et al., 2012], and in Auchenorrhyncha representatives [Frydrychová et al., 2004; Maryańska-Nadachowska et al., 2012; Golub et al., 2014; Kuznetsova et al., 2015b]. For Auchenorrhyncha, $(\mathrm{TTAGG})_{\mathrm{n}}$ is present in the families Aphrophoridae [Maryańska-Nadachowska et al., 2012], Cicadellidae [Kuznetsova et al., 2015b], Myerslopiidae [Golub et al., 2014], and Delphacidae [Frydrychová et al., 2004]. The data presented here for Cercopidae expand the knowledge of telomere types in this insect group, supporting the hypothesis that the ancestral arthropod telomere motif is conserved in Auchenorrhyncha.

The limited data for C-heterochromatin distribution in Auchenorrhyncha have shown accumulation of heterochromatin in one or both terminal/subterminal regions of the chromosomes [Kuznetsova et al., 2003, 2009, 2015b]. Here, the use of the anonymous Cot-DNA fraction that is enriched with highly repetitive DNA which is also abundant in heterochromatin, like satDNAs, revealed the accumulation of this genomic fraction mainly in terminal chromosome regions, a common location in Mahanarva as in other species of Auchenorrhyncha [Kuznetsova et al., 2009, 2015b] and as frequently reported in species with holocentric chromosomes [Spence et al., 1998; Bardella et al., 2014]. The observed difference in the size of Cot-DNA signals could suggest differential accumulation of repetitive DNAs between the species. Specifically, differences in the size of the $\mathrm{X}$ chromosome blocks were noticed, also indicating variability in the accumulation of repetitive DNAs. This pattern is more evident for M. vittata, in which the Cot-DNA hybridized in only $1 \mathrm{X}$ terminus. The $\mathrm{X}$ chromosome of $M$. vittata could represent a variation related to the subgenus Ipiranga in which $M$. vittata is included, in comparison to the subgenus Mahanarva that includes the other species. These data also suggest that differential processes of expansion or contraction of repetitive DNAs act in the X chromosome of Mahanarva that led to its diversification among the 6 species.

Interestingly, the use of the Cot-DNA fraction from $M$. quadripunctata as a probe in dot blotting against genomic DNA from the 5 other Mahanarva species revealed conservation of at least part of the highly and moderately repetitive DNA among the species. It is known that highly repetitive DNAs, especially the satDNAs, are subject to the action of several molecular mechanisms causing variation and allowing rapid evolution, generating speciesspecific sequences [Dover, 1986; Charlesworth et al.,
1994; López-Flores and Garrido-Ramos, 2012]. These molecular mechanisms could have less impact in the $\mathrm{Ma}$ hanarva genomes, as evidenced by the conservation detected here, although we do not know the type of sequences conserved because the Cot-DNA is anonymous. Therefore, analysis of specific families of satDNAs should be undertaken. Among insects, conservation of a portion of the repetitive DNA pools was observed; for example, in terminal chromosomal regions of Dichotomius beetles [Cabral-de-Mello et al., 2011] through Cot-DNA interspecies FISH, and in Triatominae species using inter-specific GISH analysis [Pita et al., 2014].

Regarding repetitive DNA base pair composition, $\mathrm{Ma}$ hanarva species appear to have a low specificity for AT or GC richness, except for $M$. tristis, with a predominance of GC blocks. Although few studies have addressed the heterochromatin base pair constitution in Auchenorrhyncha, the data show wide variation, evidencing heterogeneity for the constitutive heterochromatin composition of some species and homogeneity for others [Kuznetsova et al., 2003, 2009, 2015b]. The distinct patterns of GC-rich and neutral block distribution observed here reveal that the repetitive DNAs have diverged differently at the intragenomic level and between species, mainly between the species with 1 GC-rich block, i.e., $M$. fimbriolata, $M$. quadripunctata, and M. spectabilis, and the other species with 2 or multiple GC-rich blocks. However, some repetitive DNAs remained conserved, as demonstrated by Cot-DNA hybridization. Distinct families of repetitive DNAs differing in base pair composition could be compartmentalized in specific chromosomes among the 6 species, and are analyzed for 1 species of the genus using data from a sequenced genome [Anjos et al., in preparation]. A remarkable invariable feature among the 6 species is the presence of an interstitial GC-rich block in 1 medium-sized autosome pair, suggesting that this pair could be conserved, although other markers should be employed to confirm this statement. Finally, the data obtained from $\mathrm{CMA}_{3}$ reinforce the differentiation of the $\mathrm{X}$ chromosome (that harbors a GC-rich block) of M. vittata in relation to the other species. This differentiation was also indicated by the results of Cot-DNA FISH, and could be a characteristic of the subgenus Ipiranga.

According to Melters et al. [2012], there are no consequences associated with chromosomal rearrangements arising from fission or fusion in holocentric chromosomes, because they can segregate perfectly after these rearrangements, encouraging rapid chromosomal evolution. However, in some other clades, the rate of karyotypic evolution is not increased [Gokhman and Kuz- 
netsova, 2006; Panzera et al., 2012], as also observed here for Mahanarva. In contrast, there are some examples in which chromosomal diversity is noticed, such as Myzus persicae [Mandrioli et al., 2014] and Buthidae scorpions [Mattos et al., 2013]. Our data show that besides macrochromosomal stability, conservation for the pool of repetitive DNAs can be documented in Mahanarva species.

\section{Acknowledgements}

This study was partially supported by the Fundação de Amparo a Pesquisa do Estado de São Paulo-FAPESP (process No. 2014/11763-8) and Coordenadoria de Aperfeiçoamento de Pessoal de Nível Superior-CAPES. A.A. is supported by FAPESP (pro- cess No. 2014/06226-3). D.C.C.M. was the recipient of a research productivity fellowship from the Conselho Nacional de Desenvolvimento Científico e Tecnológico-CNPq (process No. $304758 / 2014-0$ ). The authors are grateful to the reviewers for the suggestions.

\section{Statement of Ethics}

The authors have no ethical conflicts to disclose.

\section{Disclosure Statement}

The authors have no conflicts of interest to declare.

\section{References}

-Anjos A, Ruiz-Ruano FJ, Camacho JPM, Loreto V, Cabrero J, et al: U1 snDNA clusters in grasshoppers: chromosomal dynamics and genomic organization. Heredity 114:207-219 (2015).

Bardella VB, Rosa JA, Vanzela AL: Origin and distribution of AT-rich repetitive DNA families in Triatoma infestans (Heteroptera). Infect Genet Evol 23:106-114 (2014).

- Bernardo ERA, Rocha VDF, Puga O: Espécies de cigarrinhas-das-pastagens (Hemiptera: Cercopidae) no meio-norte do Mato Grosso. Cienc Rural 33:369-371 (2003).

Boring AM: The chromosomes of the Cercopidae. Biol Bull 24:133-146 (1913).

-Cabral-de-Mello DC, Moura RC, Martins C: Chromosomal mapping of repetitive DNAs in the beetle Dichotomius geminatus provides the first evidence for an association of $5 \mathrm{~S}$ rRNA and histone $\mathrm{H} 3$ genes in insects, and repetitive DNA similarity between the $\mathrm{B}$ chromosome and A complement. Heredity 104: 393-400 (2010).

-Cabral-de-Mello DC, de Moura RC, de Souza Melo A, Martins C: Evolutionary dynamics of heterochromatin in the genome of Dichotomius beetles based on chromosomal analysis. Genetica 139:315-325 (2011).

- Carvalho GS, Webb MD: Cercopid Spittle Bugs of the New World (Hemiptera, Auchenorrhyncha, Cercopidae). (Pensoft, Sofia 2005).

-Castanhole MMU, Pereira LLV, de Souza HV, Valério JR, Barbosa LR, Itoyama MM: Meiotic chromosomes and nucleolar behavior in testicular cells of the grassland spittlebugs Deois flavopicta, Mahanarva fimbriolata and Notozulia entreriana (Hemiptera, Auchenorrhyncha). Genet Mol Biol 33:244-252 (2010).
Cavalier-Smith T: Skeletal DNA and the evolution of genome size. Annu Rev Biophys Bioeng 11:273-302 (1982).

Charlesworth B, Sniegowski P, Stephan W: The evolutionary dynamics of repetitive DNA in eukaryotes. Nature 371:215-220 (1994).

Cryan JR, Urban JM: Higher-level phylogeny of the insect order Hemiptera: is Auchenorrhyncha really paraphyletic? Syst Entomol 37: 7-21 (2012).

Dey SK: Chromosomes of five species of spittle bugs (Homoptera, Cercopidae). Cytologia 56: 523-526 (1991).

Dover GA: Molecular drive in multigene families: how biological novelties arise, spread and are assimilated. Trends Genet 2:159-165 (1986).

Elder JF, Turner BJ: Concerted evolution of repetitive DNA sequences in eukaryotes. Q Rev Biol 70:297-320 (1995).

Feschotte C, Pritham EJ: DNA transposons and the evolution of eukaryotic genomes. Annu Rev Genet 41:331-368 (2007).

Frydrychová R, Grossmann P, Trubac P, Vítková M, Marec F: Phylogenetic distribution of TTAGG telomeric repeats in insects. Genome 47:163-178 (2004).

Gokhman VE, Kuznetsova VG: Comparative in sect karyology: current state and applications. Entomol Rev 86:352-368 (2006).

-Gokhman VE, Anokhin BA, Kuznetsova VG: Distribution of $18 \mathrm{~S}$ rDNA sites and absence of the canonical TTAGG insect telomeric repeat in parasitoid Hymenoptera. Genetica 142: 317-322 (2014).

Golub NV, Kuznetsova VG, Rakitov RA: First karyotype data on the family Myerslopiidae (Hemiptera, Auchenorrhyncha, Cicadomorpha). Comp Cytogenet 8:293-300 (2014).

- Golub NV, Golub VB, Kuznetsova VG: Variability of $18 \mathrm{~S}$ rDNA loci in four lace bug species (Hemiptera, Tingidae) with the same chromosome number. Comp Cytogenet 9:513522 (2015).

\section{Groz} types, male meiosis and comparative FISH mapping of $18 \mathrm{~S}$ ribosomal DNA and telomeric (TTAGG) $)_{n}$ repeat in eight species of true bugs (Hemiptera, Heteroptera). Comp Cytogenet 5:355-374 (2011).

-Halkka O: Recombination in six homopterous families. Evolution 18:81-88 (1964).

Ijdo JW, Wells RA, Baldini A, Reeders ST: Improved telomere detection using a telomere repeat probe (TTAGGG) $n$ generated by PCR. Nucleic Acids Res 19:4780 (1991).

Kidwell MG: Transposable elements and the evolution of genome size in eukaryotes. Genetica 115:49-63 (2002).

Kuznetsova V, Aguin-Pombo D: Comparative cytogenetics of Auchenorrhyncha (Hemiptera, Homoptera): a review. ZooKeys 538:63-93 (2015).

-Kuznetsova VG, Maryanska-Nadachowska A, Nokkala S: A new approach to the Auchenorrhyncha (Hemiptera, Insecta) cytogenetics: chromosomes of the meadow spittlebug Philaenus spumarius (L.) examined using various chromosome banding techniques. Folia Biol 51:33-40 (2003).

-Kuznetsova VG, Maryanska-Nadachowska A, Nokkala S: Karyotype characterization of planthopper species Hysteropterum albaceticum Dlabola, 1983 and Agalmatium bilobum (Fieber, 1877) (Homoptera: Auchenorrhyncha : Issidae) using AgNOR-, C- and DAPI/ $\mathrm{CMA}_{3}$-banding techniques. Comp Cytogenet 3:111-123 (2009).

Kuznetsova VG, Grozeva SM, Anokhin BA: The first finding of (TTAGG) $)_{n}$ telomeric repeat in chromosomes of true bugs (Heteroptera, Belostomatidae). Comp Cytogenet 6:341-346 (2012). 
Kuznetsova V, Golub N, Aguin-Pombo D: Karyotypes, B-chromosomes and meiotic abnormalities in 13 populations of Alebra albostriella and A. wahlbergi (Hemiptera, Auchenorrhyncha, Cicadellidae) from Greece. Comp Cytogenet 7:305-325 (2013).

-Kuznetsova VG, Grozeva SM, Hartung V, Anokhin BA: First evidence for (TTAGG) $)_{\mathrm{n}}$ telomeric sequence and sex chromosome postreduction in Coleorrhyncha (Insecta, Hemiptera). Comp Cytogenet 9:523-532 (2015a).

-Kuznetsova VG, Maryanska-Nadachowska A, Anokhin B, Aguin-Pombo D: Evidence for TTAGG telomere repeats and rRNA gene clusters in leafhoppers of the genus Alebra (Hemiptera: Auchenorrhyncha: Cicadellidae). Eur J Entomol 112:207-214 (2015b).

López-Flores I, Garrido-Ramos MA: The repetitive DNA content of eukaryotic genomes. Genome Dyn 7:1-28 (2012).

Mandrioli M, Zanasi F, Manicardi GC: Karyotype rearrangements and telomere analysis in $M y$ zus persicae (Hemiptera, Aphididae) strains collected on Lavandula sp. plants. Comp Cytogenet 8:259-274 (2014).

Marin-Morales MA, Zefa E, Bertagna M, Camargo Mathias MI, Arrigoni E: Chromosome analysis of two species of sugar cane pests of the genus Mahanarva (Homoptera, Cercopidae). Caryologia 55:357-360 (2002).

- Maryańska-Nadachowska A, Kuznetsova VG, Lachowska D, Drosopoulos S: Mediterranean species of the spittlebug genus Philaenus: modes of chromosome evolution. J Insect Sci 12:54 (2012).
Mattos VF, Cella DM, Carvalho LS, Candido DM, Schneider MC: High chromosome variability and the presence of multivalent associations in buthid scorpions. Chromosome Res 21: 121-136 (2013).

Melters DP, Paliulis LV, Korf IF, Chan SWL: Holocentric chromosomes: convergent evolution, meiotic adaptations, and genomic analysis. Chromosome Res 20:579-593 (2012).

Mohan KN, Rani BS, Kulashrestha PS, Kadandale JS: Characterization of TTAGG telomeric repeats, their interstitial occurrence and constitutively active telomerase in the mealybug Planococcus lilacinus (Homoptera; Coccoidea). Chromosoma 120:165-175 (2011).

-Monti V, Giusti M, Bizzaro D, Manicardi GC, Mandrioli M: Presence of a functional $(\mathrm{TTAGG})_{\mathrm{n}}$ telomere-telomerase system in aphids. Chromosome Res 19:625-633 (2011).

Nguyen P, Sahara K, Yoshido A, Marec F: Evolutionary dynamics of rDNA clusters on chromosomes of moths and butterflies (Lepidoptera). Genetica 138:343-354 (2010).

Paladini A, Carvalho GS: Descrição de três novas espécies de Mahanarva (Hemiptera, Cercopidae, Ischnorhininae). Iheringia. Série Zool 97: 57-66 (2007)

Paladini A, Cryan JR: Nine new species of Neotropical spittlebugs (Hemiptera: Cercopidae: Ischnorhininae). Zootaxa 3519:53-68 (2012).

Palomeque T, Lorite P: Satellite DNA in insects: a review. Heredity 100:564-573 (2008).

Panzera Y, Pita S, Ferreiro MJ, Ferrandis I, Lages C, et al: High dynamics of rDNA cluster location in kissing bug holocentric chromosomes (Triatominae, Heteroptera). Cytogenet Genome Res 138:56-67 (2012).

Peck DC, Thompson V: Spittlebugs (Hemiptera: Cercopoidea), in Capinera JL (ed): Encyclopedia of Entomology, pp 3512-3516 (Springer, Dordrecht 2008).
Pinkel D, Straume T, Gray JW: Cytogenetic analysis using quantitative, high-sensitivity, fluorescence hybridization. Proc Natl Acad Sci USA 83:2934-2938 (1986).

- Pita S, Panzera F, Sánchez A, Panzera Y, Palomeque T, Lorite P: Distribution and evolution of repeated sequences in genomes of Triatominae (Hemiptera-Reduviidae) inferred from genomic in situ hybridization. PLoS One 9:e114298 (2014).

-Sahara K, Marec F, Traut W: TTAGG telomeric repeats in chromosomes of some insects and other arthropods. Chromosome Res 7:449460 (1999).

Sambrook JW, Russell D: Molecular Cloning: A Laboratory Manual, ed 3 (Cold Spring Harbor Laboratory Press, Cold Spring Harbor 2001).

-Schweizer D, Mendelak M, White MJD, Contreras N: Cytogenetics of the parthenogenetic grasshopper Warramaba virgo and its bisexual relatives. X. Patterns of fluorescent banding. Chromosoma 88:227-236 (1983).

-Spence JM, Blackman RL, Testa JM, Ready PD: A 169-base pair tandem repeat DNA marker for subtelomeric heterochromatin and chromosomal rearrangements in aphids of the Myzus persicae group. Chromosome Res 6:167-175 (1998).

Vítková M, Král JJJ, Traut W, Zrzavý J, Marec F: The evolutionary origin of insect telomeric repeats, (TTAGG) $)_{n}$. Chromosome Res 13 : 145-156 (2005).

Zwick MS, Hanson RE, Islam-Faridi MN, Stelly DM, Wing RA, et al: A rapid procedure for the isolation of $C_{0} t-1$ DNA from plants. Genome 40:138-142 (1997). 